\title{
LOCALIZATION AND REGENERATION IN THE NEURAL PLATE OF AMPHIBIAN EMBRYOS
}

\author{
WARREN H. LEWIS \\ From the Anatomical Laboratory, Johns Hopkins University \\ WITH ELEVEN FIGURES
}

EXPERIMENTS ON RANA PALUSTRIS ${ }^{1}$

It has already been shown that the dorsal and lateral lips of the blastopore of Rana palustris, when transplanted into slightly older embryos, possess considerable powers of self-differentiation into chorda, muscle, and nervous tissue. At this early stage, chorda and muscle differentiate much more completely and normally than nervous tissue. ${ }^{2}$ Evidently the cells in the lips of the blastopore destined to form nervous tissue possess to a limited extent only the power of self-differentiation when thus transplanted and removed form their normal environment, while the cells destined to from chorda and muscle have already attained greater powers of self-differentiation. ${ }^{3}$ It is of course impossible at this early stage to distinguish in the lips of the blastopore by the ordinary histological methods the cells which are to form muscle from those that are to form chorda or nervous tissue. These experiments however indicate very clearly that there are very profound differences in the cells themselves apart from any environmental differences.

\footnotetext{
1. All the embryos experimented upon, both Rana palustris and Amblystoma, were killed in Zenker's fluid, cut into serial sections, $10 \%$ in thickness, and stained in hæmatoxylin and congo red.

2 Lewis, Experiments on the regeneration and differentiation of the central nervous system in Amphibian embryos. Am. Jour. of Anat., vol. 5, 1906. Preliminary note before the Am. Ass. of Anatomists. Dec. 27, 1905.

${ }^{3}$ Lewis, Transplantation of the lips of the blastopore in Rana palustris, Am. Jour. of Anat., vol. 7, 1907.
} 
In another series of experiments on somewhat older gastrulæ of Rana palustris, small pieces were cut out anterior to the dorsal lip, from the region which later would form the anterior part of the neural plate. Such pieces when transplanted into the mesenchyme in the otic region of an older embryo continue to differentiate into nervous tissue, with nuclear and reticular zones irregularly arranged. Small irregular ventricular spaces are sometimes found and nerves are often given off into the surrounding mesenchyme. ${ }^{4}$ Most of these embryos were killed twelve days after theoperation, yet there is no indication of any degeneration of the transplanted tissue such as occurred in the nervous tissue in the preceding series. There has evidently been a considerable advance in the power of self-differentiation of this nervous tissue from that found in the lips of the blastopore of the earlier stage.

In still older gastrulæ of Rana palustris, just before closure of the blastopore when the neural plate is faintly outlined, small pieces of the neural plate were cut out and transplanted into older embryos. Piece 3, (see fig. 1), from the region of the medulla, extending from the primitive groove part way to the neural fold was transplanted in such a manner as to be entirely surrounded by mesenchyme. The embryo was killed ten days after the operation and the sections show imbedded in the mesenchyme ventral to the otic vesicle a quite normal shaped medulla. A section through it is very similar to one through the normal medulla, (see fig. 2). This small unilateral transplanted piece has developed into a perfectly bilateral structure with a large ventricle and thin roof. Even the arrangement of the nuclear and reticular zones is bilateral and shows remarkable similarity to the arrangement in the section of normal medulla seen in the same figure. The transplanted piece becomes smaller at either end and the ventricle is entirely closed. Had the piece remained in its original place in the neural plate it would probably have formed only a portion of one side of the medulla and have taken no part in the formation of the roof of the ventricle.

'Lewis, Am. Jour. of Anat., vol. 6, 1907, p. 469, figures 5 and 6. 
Piece 1, fig. 1, was transplanted in a similar manner and differentiated into what appears to be a somewhat irregular portion of the anterior end of the brain, with a small eye showing invagination and differentiation of the various layers of the retina. A nerve is given off from the caudal part of it. (figs. 3 and 4).

These two experiments alone are sufficient to indicate very clearly that the early neural plate of Rana palustris not only possesses great power of self-differentiation but that already there
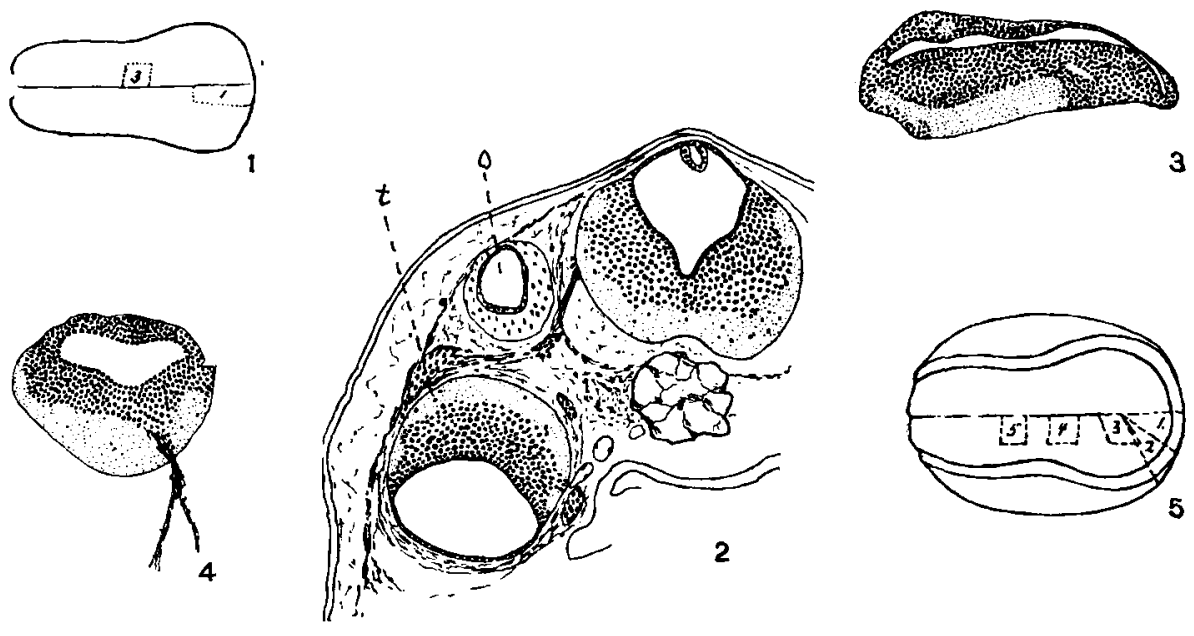

FIG. 1.-Outline neural plate Rana, pieces 1 and 3 transplanted.

FIG. 2.-Section showing transplanted piece 3 , ten days after transplantation. $t$, transplanted piece; 0 , otic capsule.

FIGs. 3 and 4.-Sections through transplanted piece 1, thirteen days after transplantation.

FIG. 5.-Outline of neural plate Amblystoma, pieces 1, 2, 3, 4 and 5, transplanted.

is a localization in the various regions of cells or groups of cells that are destined to form certain parts of the central nervous system. The ordinary histological or microscopic examination of the neural plate does not reveal these differences yet the experiments show that a small piece from the region of the neural plate which one might expect from its location would form part of the medulla will do so whether it remains in the normal position or not. 
Not only do these pieces differentiate into certain specific parts of the neural tube but they regenerate some of the surrounding parts such as the roof of the ventricle and in some cases the opposite side. In the case of piece 3 , fig. 1, which developed into the bilateal medulla-like structure (fig. 3 ) the piece was unilateral and did not extend to the edge of the neural plate so it must
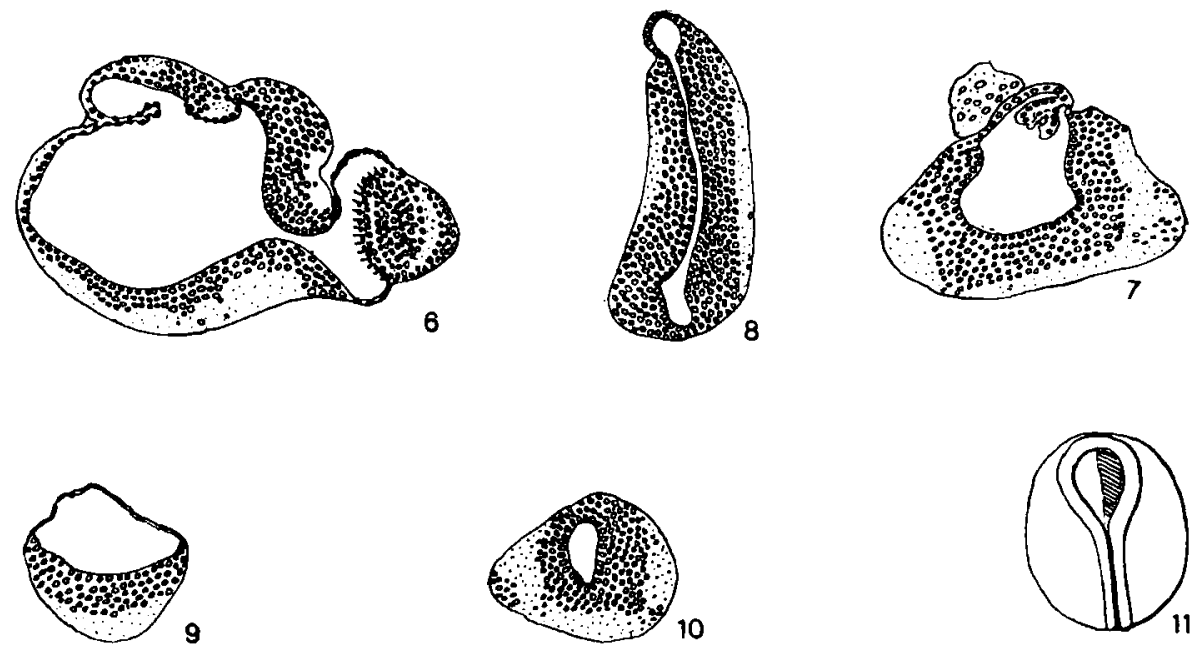

FIG. 6.-Section through transplanted piece 1, twenty-two days after transplantation.

FIG. 7.-Section through transplanted piece 2, twenty-five days after transplantation.

FIG. 8.-Section through transplanted piece 3, fifteen days after transplantation.

FIG. 9.-Section through transplanted piece 4, fifteen days after transplantation.

FIG. 10.-Section through transplanted piece 5, twenty-five days after transplantation.

FIG. 11.-Neural plate Rana palustris showing area cut away. Total regeneration followed.

have regenerated from itself the opposite half and the roof of the ventricle as well as some tissue on the same side. It has thus developed into a much more extensive piece than it would have, had it remained in the normal position. This would indicate that neighboring parts of the developing neural plate have under normal conditions a repressive influence on each other. 
These transplanted pieces of the neural plate always close over to form a neural canal, the shape of the canal or ventricle varying with the region from which the piece is taken. The power of forming a neural canal then, resides within the neural plate itself or any portion of it and is not necessarily bound up with mechanical influences from other parts of the embryo. In like manner the longitudinal foldings of the brain, its flexures or bends, are probably due to intrinsic factors within the brain itself. The transplanted piece 1 , shows indications of this process.

\section{EXPERIMENTS ON THE NEURAL PLATE OF AMBLYSTOMA PUNCTATUM}

The results obtained from many experiments on Amblystoma are similar to those from Rana palustris. As in the experiments on Rana palustris small pieces of the neural plate were cut out and transplanted into the otic region of somewhat older embryos. About one hundred and fifty such pieces were transplanted from the neural plates of twenty-seven different embryos. Two to eight pieces from each plate.

Pieces were taken from practically every region of the neural plate, and were allowed to develop in the transplanted position from ten to twenty-five days. At the time of transplantation there is no indication, other than general topographical position, of the different regions of the central nervous system. The histological picture of the arrangement and of the character of the cells is practically the same throughout the neural plate and only in later stages does the arrangement become characteristic for each portion of the central nervous system.

Fig. 5, for example, shows the position of five pieces which were cut out of the neural plate and transplanted into the otic region of an older embryo of Amblystoma. Figs. 6, 7, 8, 9 and 10 , are from sections through these pieces- $1,2,3,4$ and 5 respectively, which were allowed to develop for a number of days after the transplantation. Each piece has developed into a more or less characteristic form, corresponding somewhat to sections through the normal brain, medulla and upper part of the spinal cord. After the study of a number of such pieces and comparison 
of them with sections through the normal central nervous system it was possible, without knowing beforehand from which region of the neural plate the piece was taken, to tell quite accurately its original location.

In normal embryos killed twelve days or more after the neural plate stage, transverse sections through the various regions of the brain and cord are very characteristic for each region, not only in the general outline and shape of the outer surface and ventricle but in the arrangement of the nuclear and reticular zones as well.

The transplanted pieces always close in to form the neural canal or ventricle. The form of the external surface of the canal (ventricle), and of the walls varying according to the region from which the piece was taken. Each piece seems to develop into that portion of the central nervous system into which it would have developed had it remained in the normal position. Not only does this take place but there is to a certain extent regeneration of the opposite side.

In the region of the medulla and spinal cord this regeneration sometimes results in a bilateral structure developing from a unilateral piece. All the transplanted pieces were unilateral at the time of transplantation.

Since each piece develops into a tube-like structure no matter what its orientation may be in its strange environment, the indication is very clear that this process is dependent only on changes which go on within the piece itself. We can correctly infer from this that the rolling in of the entire neural plate, to form the tubular central nervous system, is dependent only on changes which take place within the neural plate itself and is thus quite independent of influences from the rest of the embryo.

Again, since each piece appears to develop into that portion of the central nervous system into which it would have developed had it remained in its normal position, we must conclude that at this stage every part of the neural plate possesses the power of self-differentiation and is not dependent either upon influences of other portions of the embryo or of neighboring parts of the medullary plate itself for its differentiation. The neighboring regions, however, do influence each other in a way in regulating 
the development by preventing such regions from that additional growth which they show after transplantation, such as regeneration of a portion of the opposite side or the formation of a roof to the ventricle, etc.

\section{REGENERATION}

The preceding experiments have shown that even a small piece of the neural plate possesses great regenerative power when cut out and transplanted into a strange environment. Likewise the neural plate itself has the power of regenerating small areas that have been removed.

One of my pupils, Mr. Dirge, removed a considerable portion of the floor at the anterior end of the neural plate on one side of the median line in Rana palustris. We were not aware at the time, of the power of regeneration and had hoped to remove permanently that portion of the brain which gave rise to some of the cranial nerves supplying the eye muscles of one side of the head. It was found however that even after as large a piece as is represented by the shaded area in figure 11 was removed regeneration is practically complete and so far as one can judge from serial sections the brain after two or three weeks is perfectly normal, bilateral and all the cranial nerves are present. This was repeated on a number of embryos of this stage with the same result. In some embryos however, when considerable degeneration and disintegration of the tissue about the wound followed the operation, there was often imperfect regeneration on this side of the brain. There is evidently then a limit to the power of regeneration of lost parts of the brain at this stage but within certain limits regeneration is complete.

In a number of my experiments on the transplantation of the optic vesicle a portion of the adjoining brain wall was transplanted with the optic vesicle. In the majority of these experiments the piece transplanted was not very large and regeneration of the lost part was complete. In a few, however, where larger pieces were transplanted with the optic vesicle the brain in the region 
from which the piece was taken did not succeed in regenerating the lost part entirely 'and shows defect on that side. In all embryos, however, the ventricle becomes closed, the thickness of the defective wall varying more or less with the size of the piece removed.

Accepted by the Wistar Institute of Anatomy and Biology March 20, 1910. Printed June 6, 1910. 